\title{
Physiotherapy students' perception on problem based learning
}

\author{
Thusharika D. Dissanayaka BSc \\ Temporary Lecturer, Department of Physiotherapy, Faculty of Allied Health Sciences \\ University of Peradeniya, Sri Lanka \\ E-Mail address:thushfhs@yahoo.com
}

\author{
Dr. Kosala N. Marambe MBBS, PhD \\ Senior Lecturer, Medical Education Unit \\ Faculty of Medicine, University of Peradeniya, Sri Lanka \\ E-Mail address: kosalnm@yahoo.com
}

Esther Liyanage BSc, PT, MPT

Lecturer, Department of Physiotherapy

Faculty of Allied Health Sciences, University of Peradeniya

E-Mail address: esther_3k@yahoo.com

Sri Lanka Journal of Bio-Medical Informatics 2012;3(3):75-81

doi: http://dx.doi.org/10.4038/sljbmi.v3i3.4787

\begin{abstract}
Objective: To assess the third year physiotherapy students' perception of problem based learning sessions in Musculoskeletal physiotherapy.

Design, setting and sample: Third year physiotherapy students in the department of Physiotherapy, Faculty of Allied Health Sciences, University of Peradeniya.

Measurements: A 15 item, self-administered questionnaire with a five point Likert scale was used.

Results: The response rate was 75\% (24 out of 32). Seventy nine per cent of students agreed that it promotes critical thinking. A majority of students felt that, the PBL sessions were better at fulfilling learning objectives, gave better factual knowledge of musculoskeletal physiotherapy was enjoyable and ensured team work. Most of the students' indicated that more such sessions should be organised in the future. The main disadvantage perceived was that it was time-consuming.
\end{abstract}

Conclusion: The results of this study showed that, third year physiotherapy students' perception of problem based learning sessions in musculoskeletal physiotherapy was positive. Thus it can be used as a teaching learning strategy.

Keywords - Problem Based Learning; Musculoskeletal physiotherapy; Perception; Physiotherapy student

\section{Introduction}

Problem based learning (PBL) introduced by the McMaster Medical School in the mid1960s, has become a popular teaching learning method and is used in many educational programs of health care professionals such as in medicine, dentistry, physiotherapy, occupational therapy, speech pathology, and allied health curricula all over the world ${ }^{(1,2,3,4)}$. It uses patient problems as a framework for students to acquire new knowledge and learn problem-solving skills ${ }^{(5)}$. PBL is mainly structured around small group discussions and the tutor is a part of the PBL session in facilitating the group discussion to the requisite depth $^{(6,7,8)}$, ensuring active learning.

BSc (Hons) physiotherapy degree programmes were commenced at Universities of Peradeniya and Colombo in the year 2006. It is desirable to enable students to gain 
conceptual knowledge and to apply this knowledge in the clinical setting in a self-directed manner ${ }^{(9,10)}$. However, the most commonly used teaching method in the Department of Physiotherapy, Faculty of Allied Health Sciences, University of Peradeniya is the conventional lecture discussions. Musculoskeletal physiotherapy is a main subject of the physiotherapy curriculum and it is a specialised area which discusses the diagnosis, treatment and prevention of muscle, soft tissue and joint problems.

Two published studies on PBL among medical and nursing students in Sri Lanka has stated that students have endorsed the educational benefits of PBL and their perceptions on PBL method were very positive and consider it as an effective way of learning ${ }^{(11,12)}$.

Although a considerable number of studies have investigated the student perceptions of PBL in medical and nursing curricula, its use in musculoskeletal physiotherapy remained unexplored in Sri Lanka. Therefore, the main objective of the study was to assess third year physiotherapy students' perception of PBL sessions in Musculoskeletal physiotherapy.

\section{Method}

\section{Background/settings}

The study was carried out in the department of Physiotherapy, Faculty of Allied Health Sciences, University of Peradeniya, Sri Lanka. Students enter the physiotherapy degree programme after 12 years of pre-university education. They come from varied backgrounds and their self directed learning skills are diverse.

The Faculty of Allied Health Sciences provides five four year undergraduate programs on Physiotherapy, Nursing, Radiography, Pharmacy and Medical Laboratory Sciences. First year of the physiotherapy course is dedicated to the teaching of Anatomy, Physiology, Biochemistry, Physiotherapy skills, Bio-mechanics and Research methodology. Musculoskeletal module is scheduled in the second year of this programme. This module discusses management of injuries and pathological conditions related to bones, muscles, ligaments and joints.

\section{Participants and study design}

The student cohort for this investigation comprised 32 third year undergraduate physiotherapy students of the department of Physiotherapy, Faculty of Allied Sciences, University of Peradeniya. A total of eight sessions were allocated to cover four common musculoskeletal conditions over a period of two months (April 2012 - July 2012) using PBL strategy. A deliberate effort was made to ensure that the case scenarios selected for PBL sessions were those with tremendous clinical correlations.

The 32 students were randomly divided into three groups of 11, 11, and 10 students each. The PBL procedures and processes were carefully explained to the students. The PBL materials consisted of four written problems involving hypothetical patients. These PBL clinical case histories were designed to stimulate the students to find the anatomical solution to the problems or to find the anatomical basis of the clinical conditions. The printed scenarios were circulated on Friday mornings and the group PBL discussion took place on the following Monday evenings. Each one of the case scenario was discussed in two PBL sessions. Students discussed the case scenario using their existing knowledge at the first session. At the 
second session, students discussed the case after going through given references. The materials available to the students for research were the Faculty library, personal texts, notes and electronic facilities. Electronic facilities included computer assisted learning (CAL) through storage media and browsing internet.

At the end of the PBL course (eighth session), the students were requested to evaluate these sessions by means of a self administered questionnaire which contained a five point Likert scale to indicate their responses. The questionnaire was organised in two sections: demographic details and the 15 items to obtain the students perception of the experienced PBL sessions. Students were requested to fill in the evaluation questionnaire and hand it in as they were leaving the lecture theatre. The participation was voluntary and anonymous.

\section{Results}

\section{Demographics}

The response rate was $75 \%$. Male Vs female ratio of the sample was 25: 75. Eight students were absent on the day of the study.

\section{Perception}

About $62 \%$ of the students declared that PBL gives better factual knowledge of Musculoskeletal physiotherapy and an overwhelming majority of the students perceived that PBL promotes students' critical thinking and reasoning of Musculoskeletal physiotherapy (Figure 1).

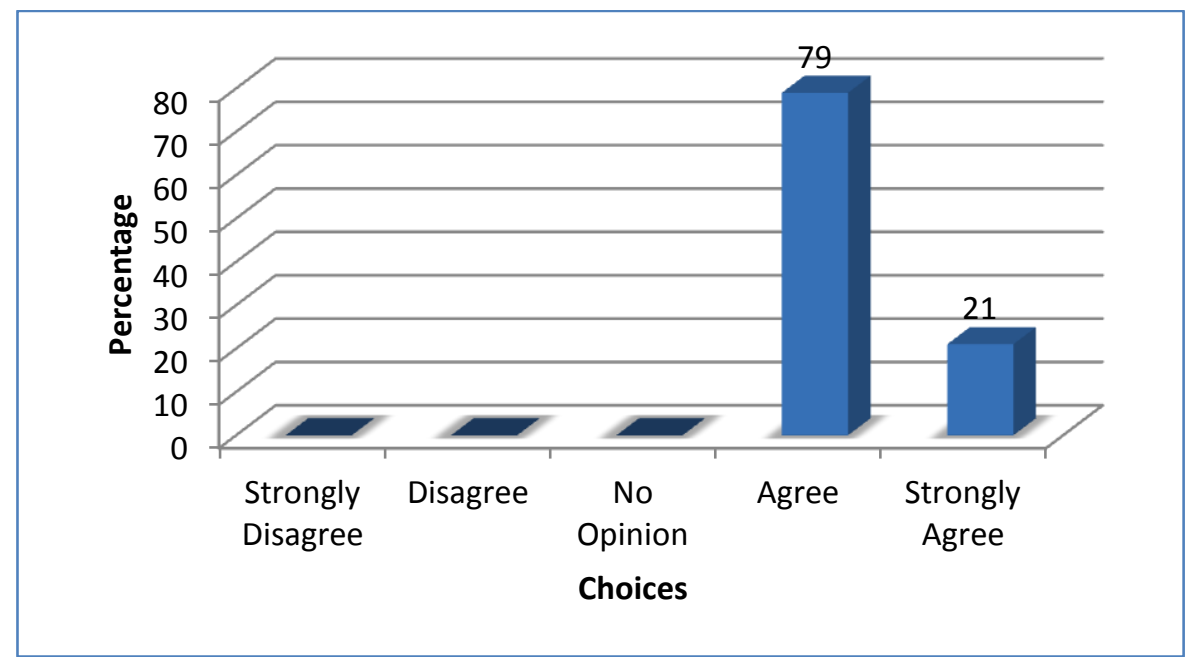

Figure1. PBL promotes students' reflective/critical thinking and reasoning of Musculoskeletal physiotherapy

While $45 \%, 54 \%$, and $62 \%$ of the students felt that the PBL sessions provided more learning fun, fulfilling the learning objectives, and gave better factual knowledge, respectively, a majority of students have expressed that they learnt to work with different social and cultural group people during this activity (Figure 2 ). 


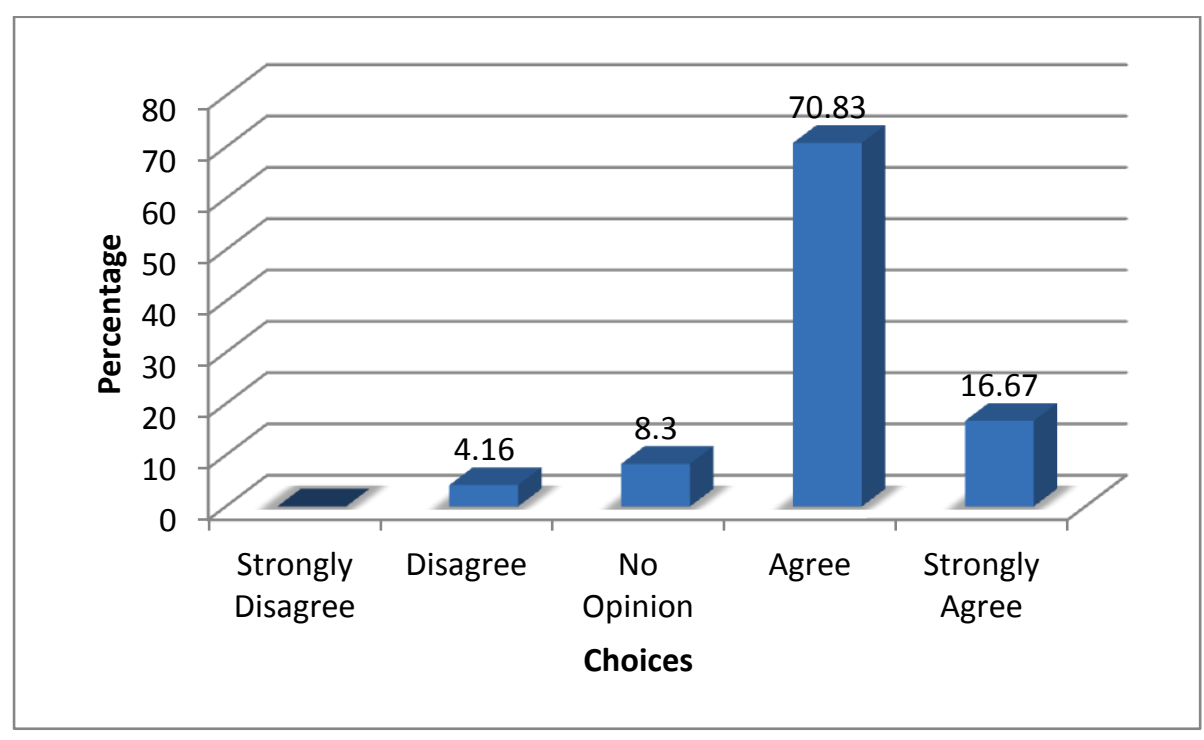

Figure 2. Learnt to work successfully with students from different social and cultural groups

In addition, $50 \%$ of students agreed that the working in a group was better than working alone. A majority of students $(83 \%)$ has appreciated the tutors' role on encouraging students' independent learning. Finally most of the students have indicated that more such sessions should be organised in future (Figure 3). However, students also indicated that it is a time consuming process.

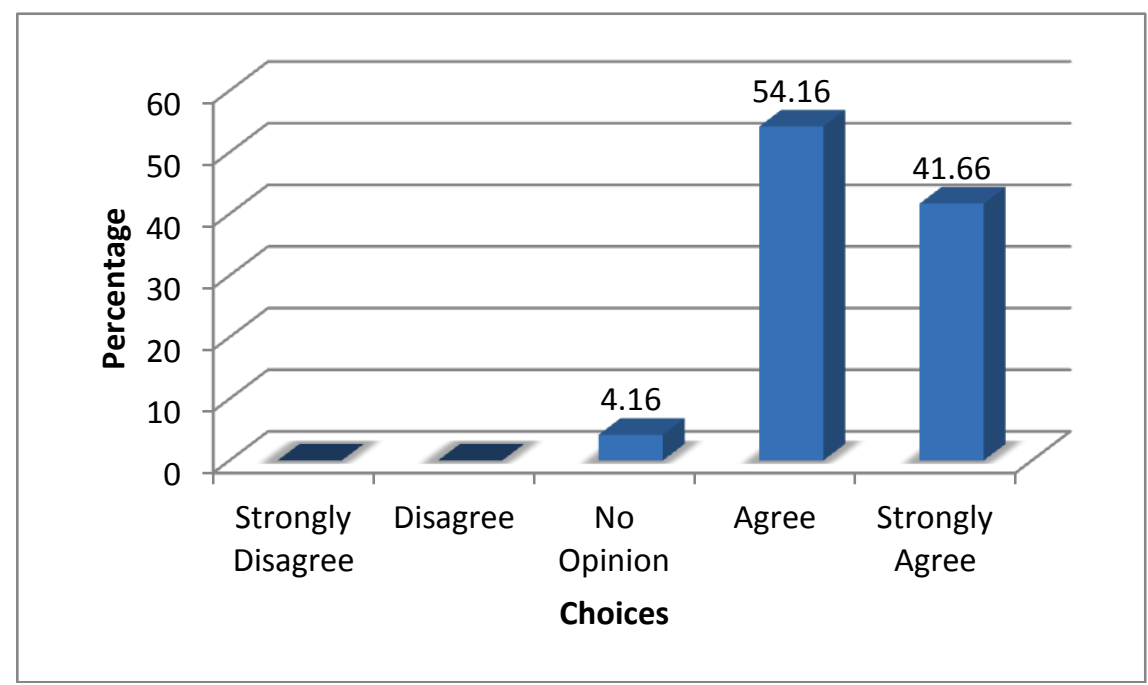

Figure 3. More Problem Based Learning (PBL) sessions should be organized

\section{Discussion}

Problem Based Learning (PBL) is a learning method which uses patient problems as a framework for students to acquire new knowledge and learn problem-solving skills ${ }^{(13)}$ under the guidance of a facilitator ${ }^{(14,15,16,17)}$. 
In keeping with the vision of producing knowledgeable and caring physiotherapists, students were provided with the PBL opportunity to enhance their self directed learning skills. This study has demonstrated that PBL is an effective way of improving critical thinking, enhancing team work and acquiring better factual knowledge of musculoskeletal physiotherapy. Learning to work successfully with students from different social and cultural groups had a high rating. Moreover, they felt that group working which helps to interact with others is the best method of learning. These findings are similar with other authors who highlight the social and affective advantage of small group tutorials ${ }^{(18,19,20)}$.

Students endorsed that PBL enhanced learning of facts, fulfilling learning objectives, reflective/critical thinking and was fun. These findings are compatible with the findings of other authors ${ }^{(21,22,23)}$. Most students stated that time consumption is the main disadvantage and that it is similar to other studies ${ }^{(24,25)}$. The reason for this could be the limited electronic facilities in the Faculty of Allied Health Sciences. It may be necessary to consider improving e-learning facilities in the faculty if allied health sciences in the future to support PBL activities. Although students have concerns over the time consuming nature they are more likely to accept PBL learning strategy in future.

\section{Conclusion}

In conclusion, the results of this study shows that third year physiotherapy students' perception of problem based learning sessions in Musculoskeletal physiotherapy is positive. Thus it can be used as a teaching learning strategy.

\section{References}

1. Chung EK, Hitchcock MA, A-Oh S, Han ER, Woo YJ. The relationship between student perception of tutor performance and tutors background in problem based learning in South Korea, International Journal of Medical Education 2011; 2: 7-11 doi: http://dx.doi.org/10.5116/ijme.4d38.d07e

2. Neufeld V, Woodward C, MacLeod SM. The McMaster M.D. program: A case study of renewal in medical education. Academic Medicine 1989; 64: 423-32

3. Hawthorne L, Minas H, Singh B. A case study in the globalization of medical education: Assisting overseas-born students at the University of Melbourne. Medical Teacher 2004; 26(2): 150-59

doi: http://dx.doi.org/10.1080/0142159032000150539

4. Wood DF. Problem based learning. British Medical Journal 2003; 326: 328-30. doi: http://dx.doi.org/10.1136/bmj.326.7384.328

5. McParland M, Noble LM, Livingston G. The effectiveness of problem based learning compared to traditional teaching in undergraduate psychiatry. Medical Education 2008; 38: $859-67$.

doi: http://dx.doi.org/10.1111/j.1365-2929.2004.01818.x 
6. Kingsburg MP. Cymn J. Problem based learning and large student group: mutually exclusive or comparable concepts- a pilot study. BMC Medical Education 2008; 8:35 doi: http://dx.doi.org/10.1186/1472-6920-8-35

7. Klegeris A, Hurren H. Impact of problem based learning in a large classroom setting: student perception and problem solving skills. Advance Physiotherapy Education 2011; 35: $408-15$

8. Reynolds F. Initial experience of inter professional problem based learning: A comparison of male and female students' view. Journal of Inter Professional Care 2003; 17: $35-44$ doi: http://dx.doi.org/10.1080/1356182021000044148

9. Entwistle N, Marton F. Knowledge objects: understandings constituted through intensive academic study. British journal of education psychology 1994; 64: 61-178 doi: http://dx.doi.org/10.1111/j.2044-8279.1994.tb01092.x

10. Renstrom L, Andersson B, Marton F. Students' conceptions of matter. Journal of Education Psychology. 1990; 82: 555-69.

doi: http://dx.doi.org/10.1037/0022-0663.82.3.555

11. Senevirathne RDA, Samarasekara DD, Karunathilake IM, Ponnalperuma GG. Students' perception of problem based learning in the medical curriculum of the Faculty of Medicine, University of Colombo. Annals of Academy of Medicine Singapore 2001; 30: $379-81$

12. Jayarathne YGSW, Marambe KN. B.Sc. Nursing Students' Perception of Problem Based Learning in the Adult Nursing Module. Proceeding of the Peradeniya University Research Sessions, Sri Lanka 2011; 16: 219

13. Albanese MA, Mitchell S. Problem-based learning: a review of literature on its outcomes and implementation issues. Academic Medicine 1993; 68: 52-81 doi: http://dx.doi.org/10.1097/00001888-199301000-00012

14. Charlin B, Mann K, Hansen P. The many faces of problem based learning: A framework for understanding and comparison. Medical Teacher 1998; 20: 323-30 doi: http://dx.doi.org/10.1080/01421599880742

15. Kaufman D, Holmes B. The relationship of tutors' content expertise to interventions and perceptions in a PBL medical curriculum. Medical Education 1998; 32: 155-261 doi: http://dx.doi.org/10.1046/j.1365-2923.1998.00158

16. Maudsley G. Roles and responsibilities of the problem-based learning tutor in the undergraduate medical curriculum. British Medical Journal 1999; 318: 657-61 doi: http://dx.doi.org/10.1136/bmj.318.7184.657

17. Maudsley G. The limits of tutors' comfort zones with four integrated knowledge themes in a problem-based undergraduate medical curriculum (Interview study). Medical Education 2003; 37(5): 417-23

doi: http://dx.doi.org/10.1046/j.1365-2923.2003.01497 
18. McLean M, Van Wyk JM, Peters-Futre EM, Higgins-Opitz SB. The small group in problem-based learning: more than a cognitive 'learning' experience for first-year medical students in a diverse population. Medical Education 2006; 28(4): e94-e103. doi: http://dx.doi.org/10.1080/01421590600726987

19. Bollinger LC. The Need for Diversity in Higher Education. Academic Medicine. 2003; 78(5): 431-36

doi: http://dx.doi.org/10.1097/00001888-200305000-00002

20. Whitla DK, Orfield G, Silen W, Teperow C, Howard C, et al. Educational Benefits of Diversity in Medical School: A survey of students. Academic Medicine. 2003; 78(5): 460-66

doi: http://dx.doi.org/10.1097/00001888-200305000-00007

21. Saalu LC, Abraham AA, Aina WD. Quantitative Evaluation of Third Year Medical Students' Perception and Satisfaction from Problem Based Learning in Anatomy: A Pilot Study of the Introduction of Problem Based Learning into the Traditional Didactic Medical Curriculum in Nigeria. Educational Research and Reviews 2010; 5(4): 193200

22. Michel MC, Bischoft A, Jakobs KH. Comparison of problem and lecture based Pharmachology teaching. Trends in Pharmacological Sciences 2002; 23(4): 168-70 doi: http://dx.doi.org/10.1016/S0165-6147(00)01940-4

23. Ozturka C, Musla GK, Diclea A. A comparison of problem based and traditional education on nursing students' critical thinking dispositions. Nurse Education Today 2008; 28(5): 627-32.

doi: http://dx.doi.org/10.1016/j.nedt.2007.10.001

24. Ozturka C, Musla GK, Diclea A. A comparison of problem based and traditional education on nursing students' critical thinking dispositions. Nurse Education Today 2008; 28(5): 627-32.

doi: http://dx.doi.org/10.1016/j.nedt.2007.10.001

25. Stokes FS, Mackinnon MM, Whitehill TL. Students' experiences of PBL. Journal and Questionnaire Analysis. Austrian Journal of Higher Education 1997; 27: 161-79. 